\title{
Determinants for selective RAR and TR recognition of direct repeat HREs
}

\author{
Thomas Perlmann, Pundi N. Rangarajan, Kazuhiko Umesono, and Ronald M. Evans \\ Howard Hughes Medical Institute, The Salk Institute for Biological Studies, La Jolla, California 92037 USA
}

\begin{abstract}
Recently, we have shown that receptors for vitamin $D_{3}$ (VDR), thyroid hormone (TR), and retinoic acid (RAR) activate preferentially through direct repeats (DRs) spaced by 3,4 , and 5 nucleotides, respectively. In addition, the RAR can activate weakly through DRs spaced by 2 nucleotides. A common feature of RAR, TR, and VDR is their ability to heterodimerize with the retinoid X receptor (RXR) through their ligand-binding domains (LBDs) to form high-affinity DNA-binding complexes that are specific for appropriately spaced repeats. In this paper we demonstrate that selective binding of RAR-RXR and TR-RXR heterodimers to their cognate DRs is a consequence of a novel cooperative dimer interaction within the DNA-binding domains (DBDs).

Accordingly, a region in the first zinc finger of the TR and RAR DBDs interacts with the second zinc finger in the RXR DBD to promote selective DNA-binding to DRs spaced by 4 and 5 nucleotides, respectively. The resulting polarity established by this interaction places RXR in the $5^{\prime}$ position of the direct repeats. These data provide a mechanism for selective receptor recognition of a restricted set of target sequences in DR DNA and explains the structural basis for physiological specificity.
\end{abstract}

[Key Words: Nuclear receptors; dimerization interfaces; DNA-binding domains; hormone response elements; direct repeats; spacing]

Received April 7, 1993; revised version accepted May 12, 1993.

Nuclear receptors comprise a large family of ligand-dependent transcription factors that display considerable specificity and selectivity in regulating the genetic programs that they ultimately influence (Evans 1988). Accordingly, one challenge is to define the molecular properties that determine the interaction of each receptors with specific target DNA sequences. Included in this family of proteins are receptors for steroids, retinoids, thyroid hormone (TR), vitamin $\mathrm{D}_{3}$ (VDR), and the insect molting hormone, ecdysone, as well as a large number of receptor-like proteins with as-yet-unidentified ligands (orphan receptors). Two classes of receptors are believed to mediate the effects of retinoids (Giguere et al. 1987; Petkovich et al. 1987; Benbrook et al. 1988; Brand et al. 1988; Krust et al. 1989; Mangelsdorf et al. 1990, 1992): the retinoic acid receptor (RAR), which binds all-trans retinoic acid (RA) and the retinoid $X$ receptor (RXR), which binds the novel RA stereoisomer 9-cis RA (Heyman et al. 1992; Levin at al. 1992).

RAR, TR, and VDR, as well as other nuclear receptors, activate transcription through DNA sequences referred to as hormone-response elements (HREs). As opposed to receptors for steroid hormones that bind to DNA as homodimers, RAR, TR, and VDR preferentially bind DNA as heterodimers with RXR (Yu et al. 1991; Bugge et al. 1992; Kliewer et al. 1992a; Leid et al. 1992; Marks et al. 1992; Zhang et al. 1992a). Furthermore, the specificities in DNA-binding of the VDR-RXR, TR-RXR, and RARRXR complexes are consistent with their activation oc- curring preferentially through direct repeats (DRs) spaced by 3, 4, and 5 nucleotides, respectively (Näär et al. 1991; Umesono et al. 1991; Vivanco Ruiz et al. 1991; Kliewer et al. 1992b|. Direct repeats spaced by 2 nucleotides also serve as RA-responsive elements that can be synergistically activated by RAR and RXR after overexpression of these receptors (Smith et al. 1991; Durand et al. 1992; Hermann et al. 1992). Recently, we have also shown that the peroxisome proliferator-activated receptor (PPAR; Isseman and Green 1990), forms heterodimers with RXR that activate transcription from the acyl-CoA oxidase gene promoter through a direct repeatlike response element spaced by 1 nucleotide (Kliewer et al. 1992b). In the presence of 9-cis RA, RXR will form homodimers that also bind to direct repeats spaced by 1 nucleotide (Zhang et al. 1992b). Thus, RXR promotes binding and selective activation from direct repeats spaced by $1-5$ nucleotides by forming homo- as well as heterodimers with at least four different members of the nuclear hormone receptor family. In addition to promoting transcriptional activation and cooperative DNAbinding to direct repeats, RXR potentiates the binding and activation of both RAR and TR to the palindromic TREp (Glass et al. 1988; Umesono et al. 1988; Zhang et al. 1992a) and of the RAR to an inverted palindrome in the $\gamma$ F-crystallin gene (Tini et al. 1993). Thus, RXR plays a central role in multiple hormonal signaling pathways by modulating receptor DNA-binding to a variety of HRES. 
Although it is clear that RAR, TR, VDR, and PPAR control specific gene regulatory networks by distinguishing between differences in the precise organization of HREs, the mechanism for such a selectivity is not understood. Because RXR is the common factor in these complexes, the ability to discriminate half-site spacing must be intrinsic to the RXR partners. Here, we demonstrate a novel interaction of the DNA-binding domains (DBDs) of RAR and TR with the DBD of RXR that promotes cooperative binding to target DNA. This proteinprotein interaction creates heterodimers that are highly selective for appropriately spaced repeats. The spacing determinant is localized to the first zinc finger of RAR, as well as TR, and is thus distinct from the DNA recognition helix (Danielsen et al. 1989; Mader et al. 1989; Umesono and Evans 1989). Together, these results explain the basis for the interaction of receptor heterodimers with distinctly spaced direct repeats.

\section{Results}

\section{Two dimerization interfaces promote binding to $\beta R E$}

To characterize regions affecting dimerization of RXR and RAR, in vitro DNA-binding experiments were performed with a set of mutant receptor proteins. Various deleted derivatives of RXR (Fig. 1A), produced by in vitro translation in rabbit reticulocyte lysates, were analyzed in gel mobility retardation assays for their ability to cooperate with RAR in binding to the palindromic TREp or the efficient RA response element identified in the RAR $\beta 2$ promoter ( $\beta R E$ ). TREp is composed of a perfect inverted repeat with no spacing, whereas the $\beta R E$ is composed of a direct repeat spaced by 5 nucleotides (Glass et al. 1988; Umesono et al. 1988, de Thé et al. 1990; Sucov et al. 1990). Lanes 1, 2, and 3 of Figure 1, B and $C$, show that binding to both the TREp and $\beta R E$ is dependent on heterodimer formation. Deletion of the RXR amino terminus (Fig. 1B, lanes 4,5) and carboxyterminal truncation to amino acid 429 did not significantly affect cooperative DNA-binding on the TREp (Fig. $1 B$, lanes 6,7 ) or to the $\beta R E$ (Fig. 1C, lanes 6,7 ). Further deletions to amino acid 413 or beyond virtually destroyed cooperative binding to TREp, confirming the existence of a region important for dimerization within the carboxy-terminal ligand-binding domains (LBDs) of these receptors (Fig. 1B, lanes 8-11; Forman et al. 1989; Glass et al. 1989; Fawell et al. 1990; Yu et al. 1991; Kliewer et al. 1992a; Leid et al. 1992; Marks et al. 1992). In contrast, whereas deletions at 413 diminished $\beta R E$ binding, a residual cooperative complex was still seen (Fig. 1C, lanes 9,11), suggesting the existence of an additional dimerization interface that selectively promotes binding to $\beta R E$ but not TREp. Use of RAR carboxy-terminal deletions to amino acids 407,386 , and 303 , together with wild-type RXR, in binding to the TREp and the $\beta R E$ indicated that the carboxy-terminal border of the corresponding region in RAR is located between amino acids 386 and 407 (data not shown). The above truncations, however, suggest that the second or aminoterminal dimer interface, (localized to the DBDs; see below) may function independently of the carboxy-terminal motif to generate the additional specificity necessary to bind direct repeat response DNA such as the $\beta R E$.
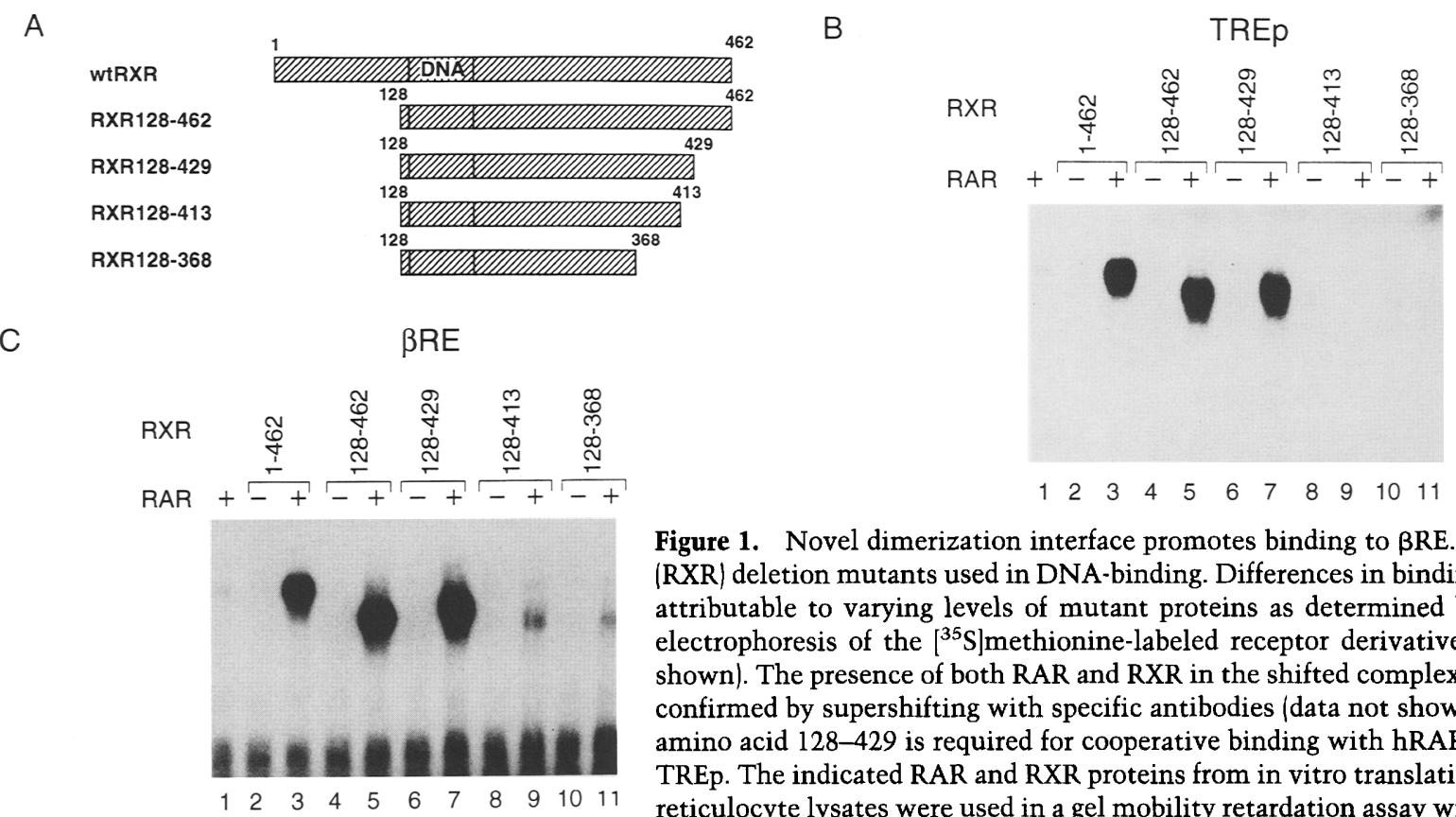

Figure 1. Novel dimerization interface promotes binding to $\beta R E .(A) \mathrm{hRXR} \alpha$ (RXR) deletion mutants used in DNA-binding. Differences in binding were not attributable to varying levels of mutant proteins as determined by SDS-gel electrophoresis of the $\left[{ }^{35} \mathrm{~S}\right]$ methionine-labeled receptor derivatives (data not shown). The presence of both RAR and RXR in the shifted complexes has been confirmed by supershifting with specific antibodies (data not shown). (B) RXR amino acid 128-429 is required for cooperative binding with hRAR $\alpha$ (RAR) to TREp. The indicated RAR and RXR proteins from in vitro translation in rabbit reticulocyte lysates were used in a gel mobility retardation assay with TREp as a ${ }^{32}$-labeled probe. Assays were performed with each RXR derivative alone (lanes 2,4,6,8,10) or in the presence of RAR (lanes $3,5,7,9,11$ ). RAR was added alone in lane $1 .(C)$ Additional dimerization interface amino-terminal of RXR amino acid 429 promotes cooperative binding with RAR to the $\beta$ RE. The indicated RAR and RXR derivatives were used as in $B$ with $\beta R E$ as a ${ }^{32} \mathrm{P}-$ labeled probe. 
A region outside of the $L B D$ is important for $R A R$ activation through $D R-5$

The above experiments suggest the existence of at least two spatially separate and functionally independent dimerization domains. Although the amino-terminal motif is sufficient to promote binding to direct repeat DNA, the presence of the carboxy-terminal motif potentiates this effect (see Fig. 1). This raises the question as to how the individual regions contribute to differential response element recognition. Accordingly, a chimeric receptor was created wherein the LBD of the TR was fused to the amino-terminal DBD-encoding region of the RAR. As shown in Figure 2A, this chimera (R/T-184/215) contains the DBD of the RAR linked to LBD of the TR. When tested on reporters containing response elements composed of $\beta$ RE half-sites spaced by 3,4 , and 5 nucleotides ( $\beta R E 3, \beta R E 4$, and $\beta R E 5$; see Fig. $2 B$ ) in transiently transfected CV-1 cells, the R/T-184/215 mutant showed the same preference as the endogenous RAR for the natural $\beta R E$ spaced by 5 nucleotides when stimulated by $\mathrm{T}_{3}$ (Fig. 2B). This indicates that the TR LBD does not significantly influence spacing preference. The R/T-184/ 215 derivative was also compared with wild-type TR for its ability to activate transcription through direct repeats spaced by 3,4 , and 5 nucleotides in transiently transfected CV-1 cells. Because TR activates more efficiently from the AGGTCA half-sites compared with the $\beta R E$ half-sites (AGTTCA) (Umesono et al. 1991; Vivanco Ruiz et al. 1991; K. Umesono, R.M. Eans, data not shown), wild-type TR and the R/T-184/215 derivative were analyzed on direct repeats containing AGGTCA half-sites (DR-3, DR-4, and DR-5; Umesono et al. 1991). As shown in Figure 2C, the R/T-184/215 derivative preferentially activated from DR-5 in contrast to TR, which shows the strongest activation from DR-4 (Fig. 2C; see also Umesono et al. 1991). Thus, although wild-type TR is selective for DR-4, the presence of the TR carboxyterminal region downstream of the RAR DBD is insufficient to redirect response element specificity. This reinforces the independence of the two dimerization motifs and the dominance of the DBDs in determining target gene specificity on DR HREs.

We then wished to test whether the entire LBD is dispensable for the DR-5 specificity of RAR. Accordingly, a RAR derivative truncated at amino acid 203, which lacks the carboxy-terminal dimerization interface (VP16RAR203*; Fig. 3A), was analyzed for its ability to activate from the $\beta R E-3, \beta R E-4$, and $\beta R E-5$ reporters. In contrast to several other nuclear receptors, carboxy-terminal truncations of RAR are only weakly active, as a result of the deletion of an essential activating region present in the LBD (Nagpal et al. 1992; P.N. Rangarajan, R.M. Evans, data not shown). To substitute for this function, the potent activation domain of herpes simplex virus VP16 was fused to the amino terminus of the receptor (Fig. 3A). This truncated receptor preferentially activated transcription in the absence of RA from the authentic $\beta R E$ (Fig. 3B) consistent with the preference for DRs spaced by 5 nucleotides shown previously for the wild-
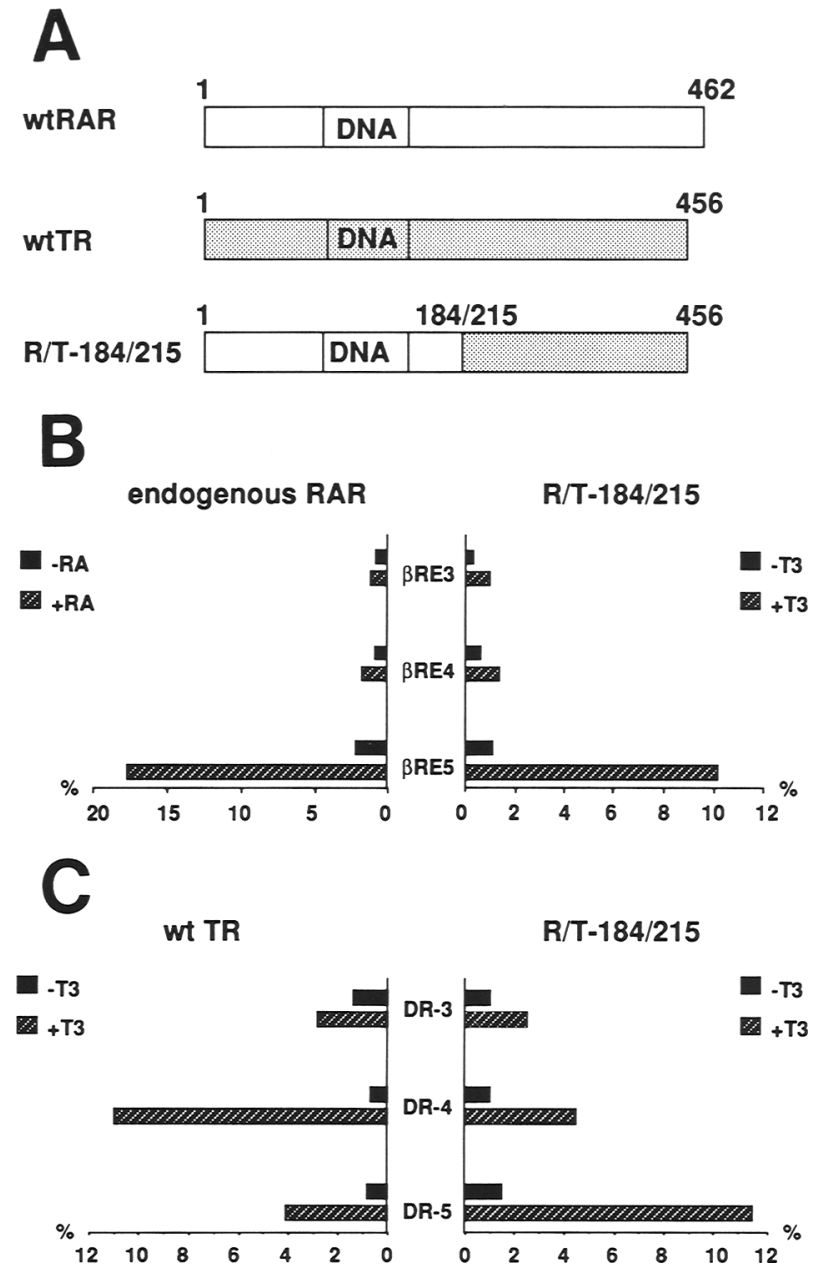

Figure 2. hRAR $\alpha$ (RAR) amino-terminal region determines DR-5 preference. $(A)$ Receptor derivatives used in cotransfection experiment in CV-1 monkey kidney cells. $(B)$ Endogenous RAR as well as $R / T-184 / 215$ activates specifically through the natural $\beta$ RE. CV-1 cells, transfected in duplicate with either $\beta R E 3$, $\beta R E 4$, or $\beta$ RE5 reporter plasmid, were treated with either ethanol (solid bars), or $1 \mu \mathrm{M}$ RA (left diagram; stippled bars). In the right diagram, the CV-1 cells were cotransfected in duplicate with R/T-184/215 and one of the reporter plasmids $\beta R-3, \beta R-4$, or $\beta R-5$ plasmid, treated with either ethanol or $100 \mathrm{nM} \mathrm{3,3}$, 5-triidothyronine $\left(\mathrm{T}_{3}\right)$ (stippled bars) as indicated, and cell extracts were assayed for CAT activity. (C) CV-1 cells were cotransfected in duplicate with either wild-type human TR $\beta$ (TR; Weinberger et al. 1986) or R/T-184/215 (RS-hTR $\beta$, RS-R/ T-84/215), and DR-3, DR-4, and DR-5 reporter plasmid ( $\Delta$ SVDR-3-CAT, $\triangle$ SV-DR-4-CAT, and $\triangle$ SV-DR-5-CAT, respectively; Umesono et al. 1991). Cells were treated with either ethanol (-) (solid bars) or $100 \mathrm{nM} \mathrm{T}_{3}$ (stippled bars), and the cells were subsequently assayed for CAT activity.

type RAR (Umesono et al. 1991). Thus, an RAR derivative lacking the carboxy-terminal dimerization domain encodes sufficient information to specify DR-5 binding in vivo, again reinforcing the existence and independence of the amino-terminal DBD encoding dimerization motif. 

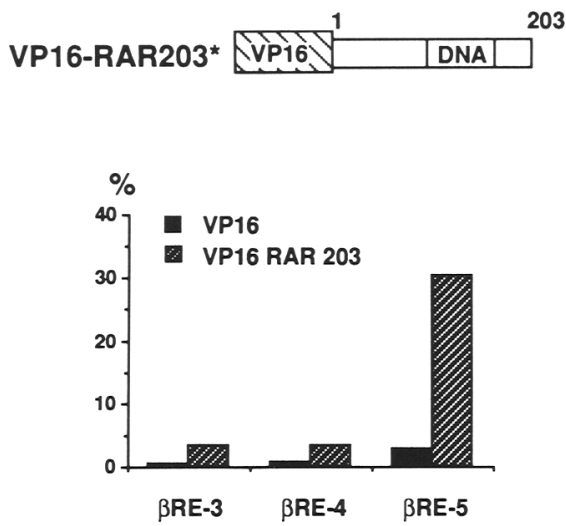

Figure 3. hRAR $\alpha$ (RAR) LBD is dispensable for DR-5 specificity in vivo. (A) VP16-RAR203 * derivative used in cotransfection experiment in CV-1 monkey kidney cells. $(B) \mathrm{CV}-1$ cells were transfected either with VP16 or VP16-RAR-203 * (pCMX-VP16, pCMX-VP16hRAR $\alpha 203^{*}$, together with reporters $\beta$ RE-3, $\beta$ RE4 , or $\beta R E-5$ as indicated, and cell extracts were assayed for CAT activity.

\section{$D B D$ s of RAR and RXR form heterodimers on $\beta R E$}

Other members of the nuclear receptor family, such as the glucocorticoid (GR) and estrogen receptors (ER), have been shown to interact through their DBDs in binding as homodimers to palindromic sequences (Kumar and Chambon 1988; Tsai et al. 1988; Luisi et al. 1991). A region in the GR second zinc finger referred to as the D-box constitutes a dimerization interface that is crucial for this interaction (Umesono and Evans 1989; Dahlman-Wright et al. 1991; Luisi et al. 1991) Because of the $180^{\circ}$ shift in relative orientation of the half-sites, the heterodimeric interaction between RAR and RXR on a direct repeat such as the $\beta R E$ is likely to be fundamentally different from the interaction in GR homodimers bound to inverted repeats. Nevertheless, the above data provide evidence for a dimerization function in the RAR and RXR DBDs. To explore this proposal, recombinant RAR (amino acids 82-167) and RXR (amino acids 130215) DBDs were expressed in Escherichia coli, purified, and used in gel mobility retardation assays. As expected, the isolated RAR and RXR DBDs, when mixed, bound cooperatively to direct repeats of the $\beta R E$, resulting in the formation of a slower migrating complex, indicative of the formation of heterodimers (Fig. 4A, lanes 4-6). In contrast, the heterodimer failed to form on a previously characterized $\mathrm{T}_{3}$-response element in the murine Moloney leukemia virus (MLV TRE) long terminal repeat, composed of a direct repeat spaced by 4 nucleotides (Sap et al. 1989; Umesono et al. 1991; Vivance-Ruiz et al. 1991) as well as on TREp, thus establishing the intrinsic ability of isolated DBDs to form heterodimers with specific DNA-binding properties (Fig. 4A, lanes 1-3; data not shown).

The selective formation of a heterodimeric complex between the two DBDs on $\beta$ RE but not the MLV TRE indicated that the cooperative interaction is sensitive to either half-site sequence or spacing. To test whether spacing is a crucial parameter, the formation of $D B D$ heterodimers was examined on a full series of $\beta R E$ spacing variants. Under high stringency conditions (see Materials and methods) dimer binding was seen only on the authentic $\beta R E$, which contains a 5-nucleotide spacer (Fig. 4B). In contrast, under lower stringency gel electrophoresis conditions, binding was observed also on the $\beta R E 2$ (Fig. 4C) consistent with previous transfection

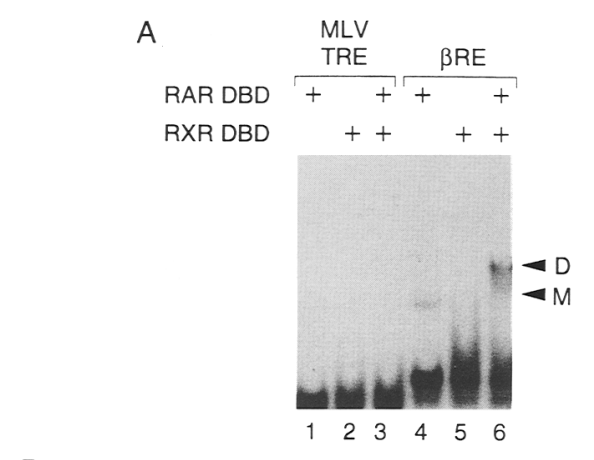

B
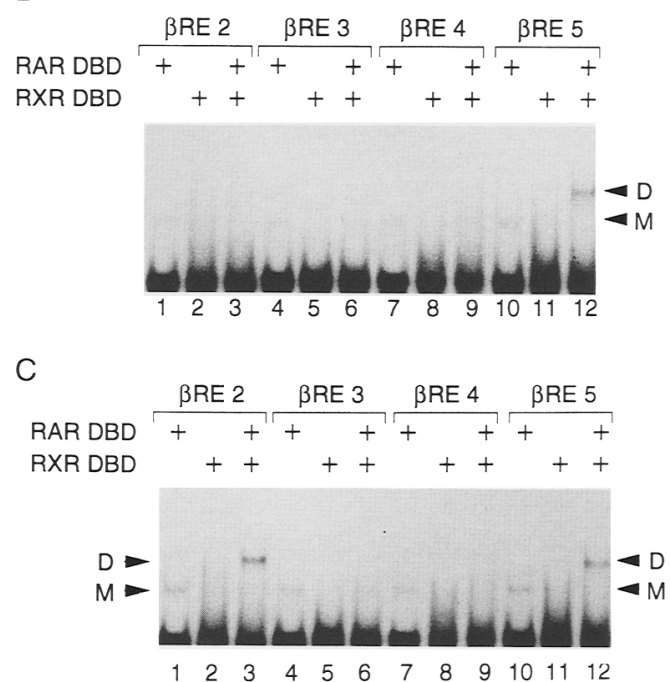

Figure 4. $h R A R \alpha(R A R)$ and $h R X R \alpha$ (RXR) DBDs form heterodimers on the $\beta R E$. (A) RAR DBD and RXR DBD $(30 \mathrm{ng})$ were incubated either alone (lanes 1,2,4,5) or together (lanes 3,6) with either the MLV TRE or $\beta R E$ as ${ }^{32} \mathrm{P}$-labeled probes and analyzed in a gel mobility retardation assay. Dimeric (D) and monomeric (M) complexes are indicated. The position of the monomer was established as the complex bound to a single half-site (data not shown). (B) The RAR DBD-RXR DBD heterodimer is specific for direct repeats spaced by 5 nucleotides. RAR DBD and RXR DBD (30 ng) were incubated either alone as indicated (lanes $1,2,4,5,7,8,10,11$ ) or together (lanes $3,6,9,12$ ) with ${ }^{32}$ P-labeled $\beta R E$ variants containing 2-5 nucleotide spacers as indicated. Dimeric (D) and monomeric $(\mathrm{M})$ complexes are indicated. $(C)$ The RAR DBD-RXR DBD heterodimer binds to $\beta R E 2$ and $\beta R E 5$ under low stringency gel mobility retardation assay conditions. RAR DBD or RXR DBD (30 ng) were incubated either alone as indicated (lanes $1,2,4,5,7,8,10,11$ ) or together (lanes 3,6,9,12) with ${ }^{32} \mathrm{P}$-labeled $\beta R E$ variants containing 2-5 nucleotide spacers. Dimeric (D) and monomeric (M) complexes are indicated. 
studies, indicating that DR-5 and DR-2 correspond to high and lower affinity response elements, respectively (Smith et al. 1991; Durand et al. 1992; Hermann et al. 1992). These results indicate that both binding specificities are attributable to protein-protein interactions within the RAR and RXR DBDs. On a $\beta R E$ containing a 1-nucleotide spacer, RXR DBDs readily form homodimers in a cooperative manner whose presence obscures evidence for heterodimer formation with the RAR DBD on such elements /S.A. Kliewer, T. Perlmann, R.M. Evans, data not shown).

\section{DBDs of TR and RXR form heterodimers on MLV TRE}

Because TR preferentially activates from direct repeats spaced by 4 nucleotides (Fig. 2C; Umesono et al. 1991), we wished to determine whether this preference was also intrinsic to the TR DBD. In parallel to the above experiments, the purified TR DBD (amino acids 97-207) is shown to form a complex with RXR that binds selectively to the MLV TRE and not the $\beta$ RE (Fig. 5A). That this selectivity is a consequence of half-site spacing is indicated in Figure 5B, where the half-site sequences are fixed and still the TR-RXR heterodimers form specifically on $\beta R E$ half-sites separated by 4 nucleotides ( $\beta R E 4$ ). These experiments indicate that a heterodimeric interface in the DBDs may represent the molecular basis underlying half-site spacing preference for receptors binding to direct repeat elements.

\section{Polarity}

The asymmetric nature of the DRs raises the question as to whether the interaction on such elements is fixed, that is, whether the two subunits bind to preferred $5^{\prime}$ and $3^{\prime}$ positions on the target DNA. To test this possibility, a region referred to as the P-box in the first zinc finger in RXR was replaced with the corresponding region from GR (Umesono et al. 1989). This derivative (RXR-G) should recognize the related GR half-site sequence AGAACA rather than AGGTCA. This mutant was tested in the presence of RAR on DRs spaced by $5 \mathrm{nu}$ - cleotides containing a GRE half-site in either the $5^{\prime}$ or the $3^{\prime}$ position of the repeat (DR5-G 5' or DR5-G 3'; see also Fig. 6A). As would be predicted, the wild-type RXR and RAR failed to bind to any of these elements (Fig. 6B). On the other hand, when RXR-G and wild-type RAR were tested, binding was seen only on the element containing a GRE half-site on the $5^{\prime}$ side. Thus, the asymmetry of the direct repeats is reflected in an asymmetric binding of the heterodimeric complex with RXR binding to the 5' half-site and RAR on the 3' half-site. Because the DBDs of RAR and RXR bind cooperatively to DR DNA, we assume that this polarity is a consequence of their physical interaction. This was confirmed by use of a RXR-G derivative in which the carboxy-terminal dimerization domain was truncated. The same preference for the element having a GRE site in the $5^{\prime}$ position was observed (Fig. 6B), although it was significantly weaker. Because DR-2 binding is less stable, we were unable to conclusively determine the orientation on such elements. Similar experiments indicated that the RXR in the RXR-TR heterodimer occupies the $5^{\prime}$ halfsite of a DR-4 element (data not shown). Thus, the DBD dimerization interfaces create spatially oriented heterodimers that bind cooperatively to DR-4 or DR- 5 with RXR in the $5^{\prime}$ position.

\section{$D B D$ dimer interfaces in $R A R$ and $R X R$}

The demonstration that the DBDs of RAR and RXR interact in an asymmetric fashion with the receptor subunits in a fixed orientation on a DR-5 prompted us to attempt to define regions conferring dimerization specificity and polarity. Individually, the RAR or the RXR DBD do not bind cooperatively to the $\beta R E$ (Fig. 4A, lanes 4,5 ; data not shown). Thus, an approach to localize regions important for cooperative interactions is to exchange sequences between the DBDs to convert the dimerization phenotype of one receptor into another. Accordingly, a series of bacterially expressed chimeras between RAR and RXR DBDs were generated (see Fig. 7A). The first two of these cnimeras, containing the aminoterminal part of RXR DBD and the carboxy-terminal se-
A

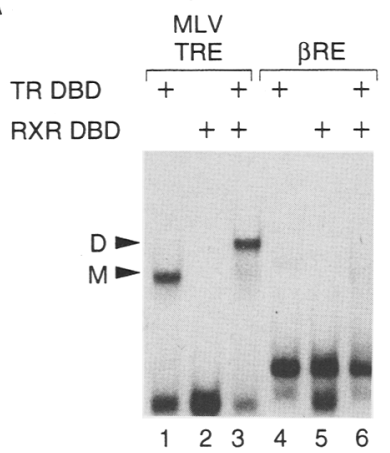

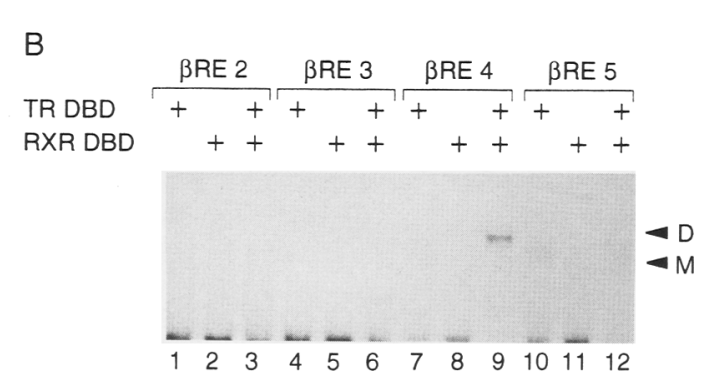

Figure 5. hTR $\beta$ (TR) and hRXR $\alpha$ (RXR) DBDs form heterodimers on the MLV TRE. (A) TR DBD and RXR DBD (30 ng) were incubated either alone (lanes $1,2,4,5)$ or together (lanes 3,6) with either the MLV TRE or $\beta R E$ as ${ }^{32} \mathrm{P}$-labeled probes and analyzed in a gel mobility retardation assay. Heterodimeric (D) and monomeric (M) complexes are indicated. $(B)$ The TR DBD-RXR DBD heterodimer is specific for direct repeats spaced by 4 nucleotides. TR DBD and RXR DBD ( 80 and $30 \mathrm{ng}$, respectively) were incubated either alone (lanes $1,2,4,5,7,8,10$, 11) or together (lanes $3,6,9,12$ ) with ${ }^{32} \mathrm{P}$-la-

beled $\beta R E$ probes containing 2-5 nucleotide spacers as indicated and analyzed in a gel mobility retardation assay. Heterodimeric (D) and monomeric $(\mathrm{M})$ complexes are indicated. 
A

DR5-G-5' AGAACA ccgaa AGGTCA

DR5-G-3' AGGTCA ccgaa AG $\triangle A C A$
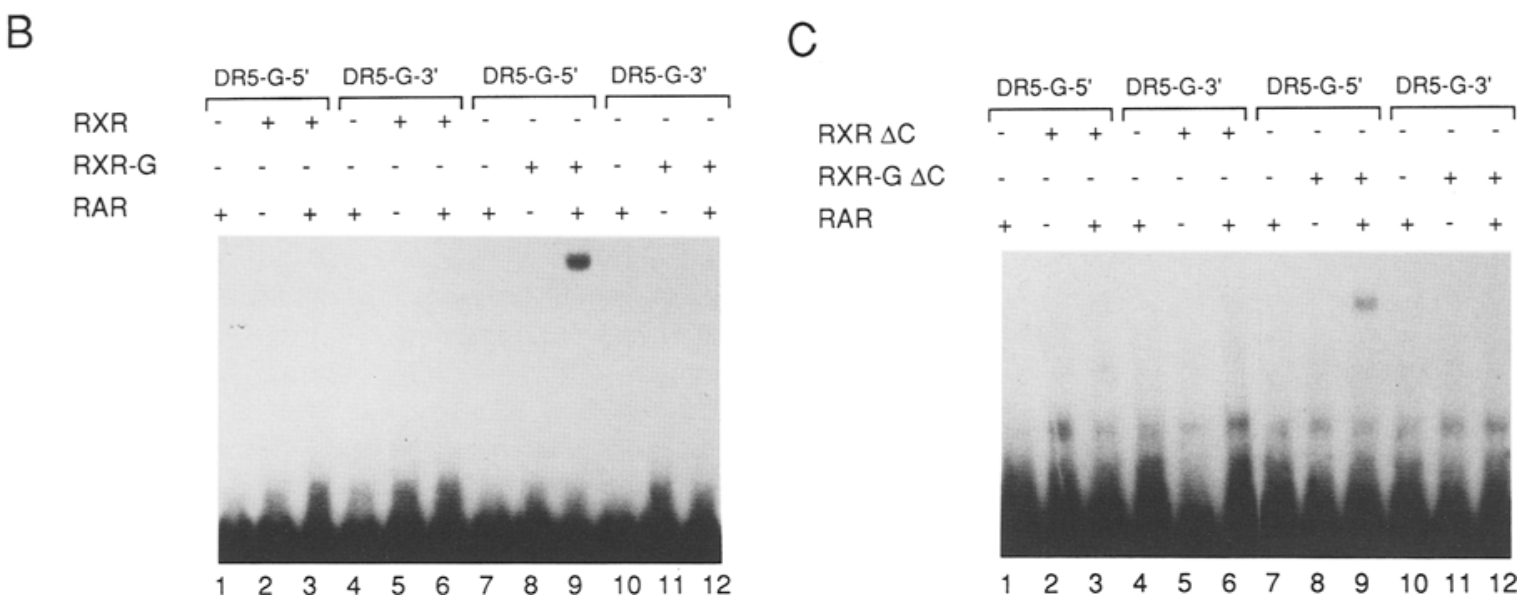

Figure 6. The heterodimeric complex is intrisically asymmetric. $(A)$ Sequences of the two variant DR-5 oligonucleotides used for binding. DR5-G-5' and DR5-G-3' contain the GRE half-site (AGAACA; two central A residues are boxed) in either the 5' or in the 3' position. (B) RXR and RXR-G were assayed either alone (RXR, lanes 2,6; RXR-G, lanes 8,11) or in the presence of RAR (lanes 3,6,9,12) with either DR5-G-5' (lanes 1,2,3,7,8,9) or DR5-G-3' (lanes 4,5,6,10,11,12) as ${ }^{32}$ P-labeled probes. (C) RXR $\Delta C$ (RXR truncated at amino acid 386) or RXR-G $\Delta$ C (RXR-G truncated at amino acid 386) were assayed either alone or in the presence of RAR as above.

quences from RAR DBD (X/R 200/153 and X/R 185/ 138), maintained an RXR phenotype in the formation of heterodimers with RAR DBD on a $\beta R E$ (Fig. $7 B$, lanes 4-7). This indicates that the most carboxy-terminal region of the RXR DBD does not encode the dimer interface motif. When RAR sequences replaced all of the second zinc finger of RXR, however, the resulting chimera was unable to heterodimerize with the RAR DBD /X/R 168/121; Fig. 7B, lanes 8,9l, indicating that the RXR dimerization interface maps to the D-box and adjacent sequences in the second zinc finger (referred to as the D-box region).

In contrast to RXR, RAR does not depend on its D-box region for DBD heterodimerization because its presence or absence does not promote or inhibit the ability of chimeras to heterodimerize with RXR DBD (Fig. 7C, lanes 4-9|. Instead, as shown by the last three DBD derivatives in Figure 7A containing amino-terminal sequences of RAR, a portion of the RAR first zinc finger (to amino acid 103) is necessary and sufficient for heterodimerization with RXR DBD (Fig. 7C, lanes 10-15). For simplicity we refer to this region as the direct repeat box (DR-box).

The last two derivatives illustrated in Figure 7A are unusual in that they contain both the RXR D-box region and the RAR DR-box and, in principle, could allow for three distinct interactions. First (as shown above), the DR-box of RAR could permit heterodimer formation with RXR. Second, the D-box region could permit heterodimer formation with the RAR DBD. Third, the presence of both interfaces could allow homodimeric interactions. As predicted, these chimeras bind efficiently as homodimers to the $\beta R E$ (Fig. $7 \mathrm{~B}, \mathrm{C}$, lanes 12,14 ), as well as forming the predicted heterodimers with both RAR and RXR DBDs (Fig. 7B,C, lanes 13,15). Furthermore, the homodimers maintain the spacing restriction because they selectively bind the $\beta R E$ (DR-5) when tested on direct repeats spaced by $2-5$ nucleotides (data not shown, see below). These data support the proposal that the first finger of the RAR DBD contains a dimerization interface that interacts with the RXR D-box region to promote heterodimeric binding to direct repeat DNA. Furthermore, our data suggest that these subdomains constitute physically independent and somewhat modular structural units (see Discussion).

\section{First zinc finger: determinant of spacing}

The above results suggested a configuration of the heterodimer such that part of the first zinc finger of RAR /to amino acid 103) specifies spacing preference. Among the receptors that so far have been shown to heterodimerize with RXR, only RAR preferentially activates and binds to half-sites spaced by 5 nucleotides. This would predict that the binding specificity of RAR should be reflected in unique features in the RAR first zinc finger. Several differences exist between RAR and the other RXR partners, which may account for the binding specificity of RAR (see Fig. 8A). For example, the DBDs of RAR and TR differ by 8 amino acids within the first zinc finger. We demonstrated above that TR specifically activates through direct repeats spaced by 4 nucleotides and that this preference was encoded by the DBD (see Fig. 2C and $5 B)$. To test whether the first zinc finger region in TR serves a similar role to the RAR DR-box in determining 

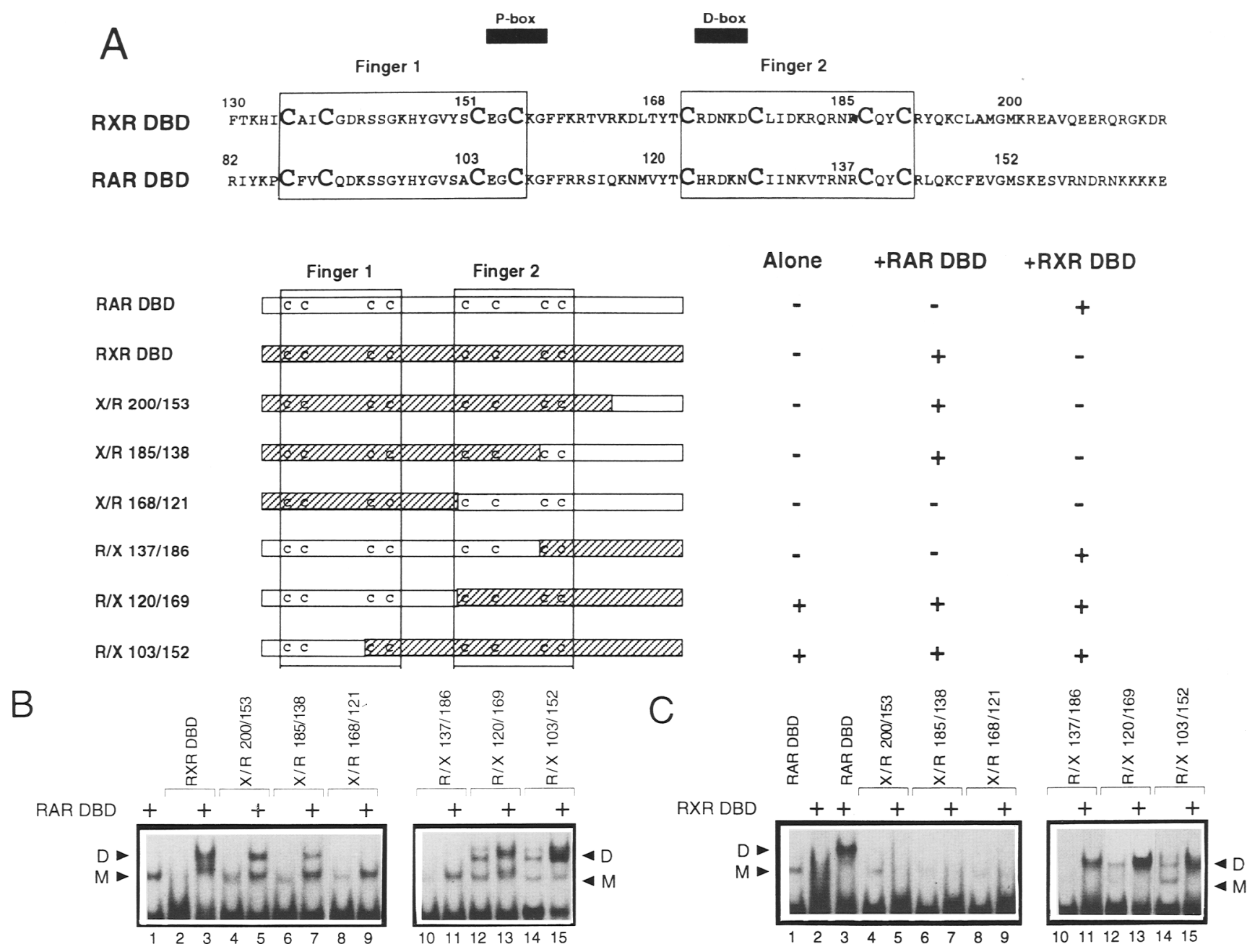

RXR DBD

Figure 7. Heterodimerization through two distinct regions in the hRAR $\alpha(R A R)$ and hRXR $\alpha(R X R) D B D s$. (A) Illustration of chimeric DBDs used in gel mobility retardation analysis. RXR DBD and RAR DBD amino acid sequences are shown. The first and second zinc fingers are indicated as are the positions of the previously defined P- and D-boxes (Umesono and Evans 1989). In the chimeras, RAR sequences are indicated as open bars and RXR as stippled bars. Numbers indicate the last and the first amino acids in respective DBDs at the breakpoint between RAR and RXR sequences. A summary of the results from gel mobility retardation assays are shown, indicating formation of dimers $|+|$ or no formation of dimers $|-|$ when DBDs were incubated alone and together with RAR DBD $\mid+$ RAR DBD) or RXR DBD (+ RXR DBD). Each DBD derivative was titrated to unambiguously determine their ability to form homodimers in a cooperative manner (data not shown). $\beta$ RE was used as ${ }^{32} \mathrm{P}$-labeled probe in gel mobility retardation assays. (B) Chimeras analyzed in a gel mobility retardation assay with or without RAR DBD. Chimeras were added either alone $($ lanes $2,4,6,8,10,12,14)$ or with RAR DBD (lane 3,5,7,9,11,13,15) (lane 1) RAR DBD alone; (lane 2) RXR DBD alone; (lane 3) RAR and RXR DBDs. Dimeric (D) and monomeric $(M)$ complexes are indicated. $(C)$ Chimeras analyzed in gel mobility retardation assays with or without RXR DBD. Chimeras were added either alone (lanes $2,4,6,8,10,12,14$ ) or with RXR DBD (lanes $3,5,7,9,11,13,15)$. RAR DBD was added alone in lane 1. RXR DBD was added alone in lane 2 or with RAR DBD in lane 3.

half-site spacing preference, we produced a chimeric DBD (T/X DBD 97/152) similar to R/X DBD 103/152 (Fig. 7A) but containing the first zinc finger region of TR instead of RAR (see Fig. 8B). In contrast to the R/X DBD $103 / 152$ chimera, which homodimerized only on direct repeats spaced by 5 nucleotides, the T/X DBD 97/152 showed no binding to the $\beta R E-3$ and a clear preference for half-sites spaced by 4 nucleotides relative to $\beta R E-5$ (Fig. 8B). This is consistent with the specificity of the wild-type TR in transcriptional activation and in DNAbinding as a heterodimer with RXR and supports the hypothesis that the TR first finger acts as a determinant of half-site spacing.

\section{Discussion}

A unique feature of RXR is its central role in modulating a number of hormonal signaling pathways through the formation of heterodimers with VDR, TR, RAR, and the orphan receptor PPAR. Previously, these receptors were shown to preferentially recognize and activate through HREs composed of direct repeats of a common half-site 
A

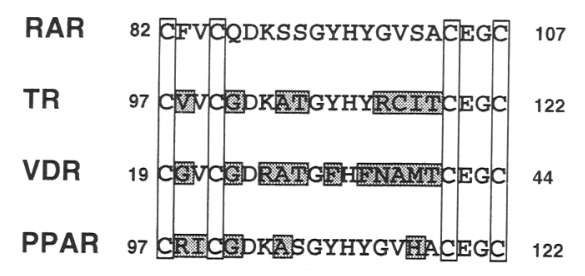

B

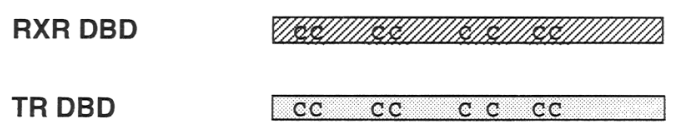

T/X 118/152DBD

C

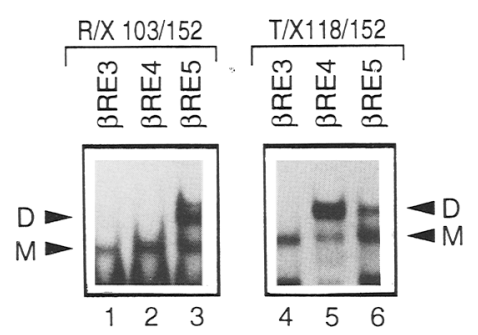

Figure 8. The first zinc finger of hRAR $\alpha$ (RAR) and human TR $\beta$ (TR) determines spacing preference. (A) Amino acid sequences of the first zinc fingers of human RAR (Giguere et al. 1987), TR (Weinberger et al. 1986), VDR (Baker et al. 1988), and mouse PPAR (Isseman and Green 1990). Conserved cysteines are boxed. Amino acid differences are shaded. (B) RXR DBD (hatched bar), TR DBD amino acids 97-207 (shaded bar), and chimeric T/X 118/152 DBD. Breakpoints are at hTR $\beta$ amino acid 118 and RXR amino acid 152. $(C)$ First finger region of RAR and TR directs spacing preference for $\beta R E-5$ and $\beta R E-4$, respectively. R/X 103/152 or T/X 118/152 was incubated with ${ }^{32} \mathrm{P}$ labeled $\beta$ RE-3, $\beta$ RE- 4 , or $\beta$ RE- 5 probes in a gel mobility retardation assay. $\mathrm{R} / \mathrm{X} 103 / 152$ forms dimers only on the $\beta \mathrm{RE}-5$ element, whereas T/X 118/152 preferentially forms dimers on the $\beta R E-4$ element. Dimeric (D) and monomeric (M) complexes are indicated.

sequence. This led to the definition of a simple physiologic code in which half-site spacing plays a critical role in achieving selective hormonal response (Mangelsdorf et al. 1991; Näär et al. 1991; Umesono et al. 1991; Vivanco Ruiz et al. 1991; Kliewer et al. 1992b). Direct repeat HREs stand in contrast to response elements recognized by steroid receptors, which are composed of inverted repeats. Thus, molecular interactions whereby VDR, TR, and RAR recognize DRs as heterodimers with RXR must be fundamentally different from those through which steroid receptors recognize inverted repeats. Our present study implicates the DBDs of RAR and TR as necessary and sufficient for the ability to bind as heterodimers with the RXR DBD to appropriately spaced direct repeats. Thus, our data demonstrate that an asymmetric protein-protein interaction underlies the molecular basis for specific and cooperative DNA-binding of receptor heterodimers to tandem repeat HREs.

\section{The DR-box in direct repeat recognition}

Studies of the steroid receptors have identified two regions that are important for the formation of homodimers and cooperative binding to inverted repeat HREs. First, a discrete region in the carboxy-terminal LBD of the estrogen receptor (and other receptors) promotes efficient dimerization and cooperative DNA-binding (Fawell et al. 1990). Second, a segment, referred to as the D-box, constitutes a dimerization interface in the GR DBD that selectively promotes the recognition of inverted repeat GREs (Umesono and Evans 1989; Dahlman-Wright et al. 1991; Luisi et al. 1991). In the case of the RAR, TR, and VDR, previous studies have focused on the carboxy-terminal LBD as mediating heterodimer formation (Glass et al. 1989; Forman et al. 1989; Fawell et al. 1990; Yu et al. 1991; Kliewer et al. 1992a; Leid et al. 1992; Marks et al. 1992). The isolated LBD of RAR can form heterodimers in solution (Kliewer et al. 1992a). For these reasons, we anticipated the direct repeat determinant to be localized to the LBD. Unexpectedly, our studies identify a novel dimer interface (DR-box) in the DBDs of RAR and TR. The DR-box, situated in the first zinc finger loop, is apparently crucial in establishing spacing preference to cognate DRs through interactions with the RXR D-box region.

The interaction of the DR-box with the RXR D-box region leads to several important conclusions. First, whereas the D-box functions as a dimerization interface, a domain that is conserved with the steroid receptors, the DR-box is novel and functions as a distinct asymmetric protein-protein interface to generate a DNAbinding unit. It is this asymmetry that allows RAR and TR to bind to direct repeat DNA. Second, the D-box region, although participating in heterodimer formation, does not impart spacing restriction as in the GR. Rather, it serves as a common acceptor for RAR and TR wherein the DR-box now encodes spacing information. Third, the DR-boxes of RAR and TR appear not to promote selective binding to cognate DRs in the absence of RXR. Rather, selectivity is dependent on the asymmetric interactions with RXR through the DR-box.

The modular characteristics of the DR-boxes is indicated by the experiments showing that this region appears to be interchangeable between RAR and TR. Interestingly, in VDR, TR, and RAR, the DR and D-boxes, are localized on separate exons (Laudet et al. 1991; Lehmann et al. 1991; van der Leede et al. 1992). From an evolutionary point of view, such modularity could have several advantages. First, the existence of such distinct modules suggests a mechanism by which changes in the DR-box may result in the recognition of novel motifs with different spacing between half-sites, thus linking new receptors into distinct regulatory pathways. Second, by mechanisms such as exon shuffling and/or gene conversion, $D R$ and D-boxes may be recombined in new receptors. This may result in the acquisition of novel properties such as the ability to homodimerize or heterodimerize with novel partners. For example, a homotypic phenotype would be achieved if both of the re- 
quired dimerization interfaces are present within the same molecule, as is the case with the homodimerizing chimeras created in this study (see Fig. 7 and 8). Also wild-type receptors, such as COUP and HNF-4 as well as RXR (in the presence of 9-cis RA), have been shown to bind direct repeat HREs as homodimers (Sladek et al. 1990; Cooney et al. 1992; Zhang et al. 1992).

\section{Asymmetry in heterodimer-HRE interaction}

As described above, the binding to direct repeat DNA generates an intrinsically asymmetric complex. Our results ascribe an orientation of the heterodimer complex bound to cognate HREs such that the RXR monomer resides in the $5^{\prime}$ portion of the repeat (see Fig. 6). It is important to ask whether the DR- and D-box regions have the potential to interact in such a configuration. In the GR-GRE complex, the GR D-box points into the spacer between the half-sites of the GRE to mediate a homotypic interaction between the monomers (Luisi et al. 1991), as illustrated in Fig. 9A. In the interaction with a direct repeat HRE, it is reasonable to assume that RXR interacts in a similar fashion with AGGTCA motifs as the GR on the related AGAACA GRE half-site. With RXR in the $5^{\prime}$ half-site its D-box and adjacent sequences would be oriented toward the spacer (Fig. 9B). On the other hand, RAR or TR occupying the 3' half-site orients the opposite face (including the DR-box; see also Luisi et al. 1991) toward the spacer. The DR-box of RAR and TR is therefore available for interaction with the RXR D-box region as illustrated in Figure 9B. According to this view, the DR-box would function as a type of molecular ruler to spatially position the P-box DNA recognition helices for complementary interaction with appropriately spaced half-sites.

Our model indicates that regions extending carboxyterminal of the RAR second zinc finger are in a position to participate in additional protein-protein interactions (see Fig. 9B). Wilson et al. (1992) have identified a sequence in this region to be important for the binding of RXR homodimers to DRs spaced by 1 nucleotide (referred to as the T-box). Interestingly, two-dimensional NMR analysis has revealed an additional $\alpha$-helix localized in this region (Lee et al. 1993). Although a similar role of this region in RAR and TR has yet to be demonstrated, this does not preclude other regions outside of the DR- and D-boxes from contributing to dimer formation. It is important, however, to emphasize that our analysis has focused on sequences determining differences in half-site spacing that clearly do not localize to the T-box region.

\section{Perspectives}

Our results have demonstrated a common strategy by which RAR and TR select their cognate DRs (DR-5 and DR-4, respectively). We speculate that VDR (DR-3) may interact with RXR in a similar orientation. However, because of changes in rotational shift between differently spaced half-sites, as well as a decreased distance
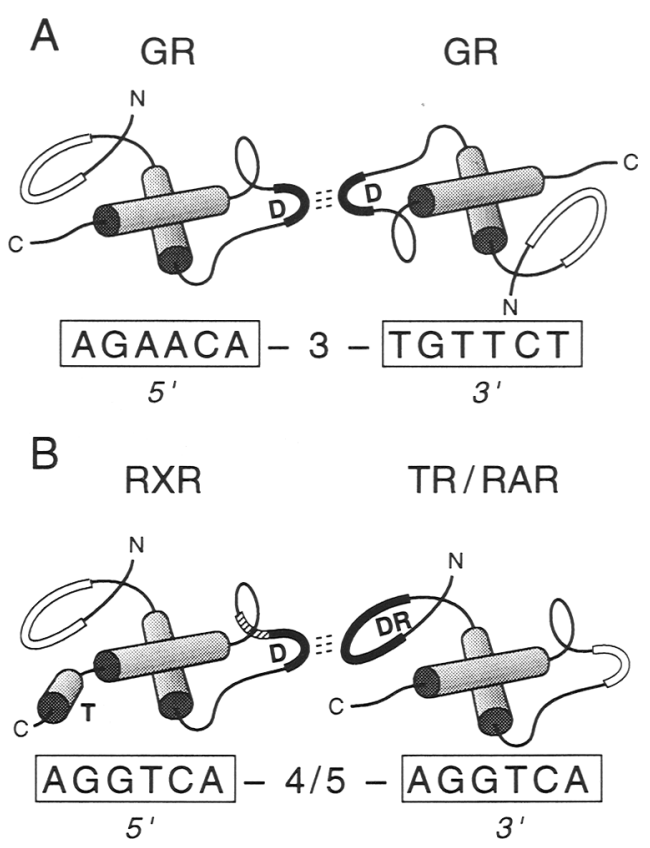

Figure 9. (A) Schematic illustration of the GR DBD homodimer bound to the inverted repeat GRE. The GR D-box (D, solid curve/ points into the spacer of the inverted repeat to mediate the homotypic interaction between monomers. The region corresponding to the DR-box in RAR and TR (open curve) is not utilized in this interaction (Luisi et al. 1991). (B) Suggested model for the RXR DBD heterodimeric complexes with either TR or RAR DBDs on direct repeat HREs spaced by 4 (TR) or 5 (RAR) nucleotides. Assuming that RXR interacts with the similar polarity as GR on the related half-site AGGTCA, the RXR D-box (D, filled) and adjacent sequences (stippled) point into the spacer region to allow contacts to be established with the TR or RAR DR-box (DR; solid curve). The regions corresponding to the RAR and TR DR-box in RXR (open) and the RXR D-box in RAR and TR (open) would not participate in this interaction. This is consistent with our data using chimeric DBDs. Also indicated is the additional carboxy-terminal $\alpha$-helix in RXR corresponding to the T-box (Wilson et al. 1992; Lee et al. 1993). A consequence of our model would predict that RXR occupies the $5^{\prime}$ half-site and TR or RAR the $3^{\prime}$ half-site.

between bound monomers, different dimerization regions may be present in receptors binding to DR-1 and DR-2 motifs. Thus, the actual positions of the DR-box and its target for interaction in RXR may vary in different heterodimeric complexes. For example, several recent studies suggest that RAR-RXR heterodimers also bind to response elements composed of DRs spaced by 2 nucleotides (Smith et al. 1991; Durand et al. 1992; Hermann et al. 1992; T. Ogura and R.M. Evans, unpubl.). In vitro, we find that RAR and RXR DBDs will form heterodimers on DR-2 HREs, but these are less stable than the DR-5 complex (see Fig. 4B,C). Accordingly, we view the DR-2 as an alternative lower affinity response element. Again, because of a $105^{\circ}$ rotational shift and $10 \AA$ reduction in monomer spacing, an alternative dimerization interface may be used in RAR-RXR binding to DR-2 motifs. 
A paradox is that both the RAR and TR can bind and activate through palindromic response elements such as the TREp (Fig. 1B; Bugge et al. 1992; Leid et al. 1992; Marks et al. 1992; Zhang et al. 1992a). Binding to a palindromic response element, however, would suggest that the DR and D-box interactions are not involved because they could not be properly aligned. This is supported by our observation that isolated TR and RAR DBDs are not capable of cooperative binding to inverted repeat DNA with or without RXR. In contrast, the intact receptors are capable of cooperative binding to inverted repeat DNA, suggesting a primary role for the carboxy-terminal dimerization motif in this process.

The presence of multiple, independent, and cooperative dimerization motifs seems to impart impressive flexibility in the binding properties of RAR and RXR heterodimers. This would suggest that highest affinity binding occurs through a two-step mechanism in which heterodimeric complexes are first formed in solution via the carboxy-terminal motif, and the complex specificity is further enhanced by additional cooperative interactions within the DNA-binding domain itself. Recent studies have shown that the Drosophila ultraspiracle (usp) gene product is able to substitute for RXR in heterodimer formation with the PPAR, VDR, TR, and the RAR (Yao et al. 1992). These usp heterodimers display specificity for the appropriately spaced response elements for each of these receptors. In addition, usp forms a heterodimer with the ecdysone receptor, indicating the generality of this phenomenon. Because RXR/usp proteins serve as common partners for a variety of nuclear receptors, the results of this study may stand as a general paradigm for a broad class of receptor-DNA interactions. Together, this work is consistent with, and supports, the proposed existence of a physiologic code built into DNA by which receptor selectivity is achieved through differences in half-site spacing.

\section{Materials and methods}

Plasmids

The pRS-hTR $\beta$ expression plasmid used in the cotransfection assays has been described previously (Thompson and Evans 1989). R/T-184/215 was made by inserting an MluI-SacI fragment from RS-hRAR $\alpha$ (Giguere et al. 1987), encompassing sequences for the hRAR $\alpha$ DBD into Mlul/SacI-cut RS-hTR $\beta$. For the construction of the VP16 expression vectors the sequence for the VP16 trans-activation domain was amplified by PCR from the pVP16C1 (Novagen, Wisconsin) and cloned at the HindIII site of pCMX vector (Umesono et al. 1991) to generate pCMX-VP16. The MscI-PvuII fragment encoding 203 aminoterminal amino acids of hRAR $\alpha$ was fused in-frame at the EcoRV site of pCMX-VP16 to generate VP16-RAR $203^{*}$. Reporters used in the transfection assays have been described (Umesono et al. 1991), except for $\triangle$ SV- $\beta R E-3-C A T$, which was made by cloning the oligo AAGCTTAAGGGTTCACGAAGTTCACTCGCATAGCTT and its complement into $\triangle$ SV-CAT. Templates for carboxy-terminal truncated receptors were produced by a PCR approach described previously (Sarkar and Sommer 1989; Höög et al. 1991). Accordingly, primer sequences were chosen to correspond to the desired truncation end points.
All 5' primers contained the T7 promoter and an optimal translational start site for subsequent use in in vitro transcription with T7 RNA polymerase (Boehringer) and translation in rabbit reticulocyte lysates (Promega). All proteins were $\left[{ }^{35} \mathrm{~S}\right]$-methionine labeled and analyzed by electrophoreses on $10 \%$ SDS-polyacrylamide gels. Plasmids containing the complete coding sequences of hRXR $\alpha$ (RS-hRXR $\alpha)$ and hRAR $\alpha$ (RS-hRAR $\alpha$ ) were used as templates in these reactions (Giguere et al. 1987; Mangelsdorf et al. 1990|. For the construction of bacterial expression vectors, hRAR $\alpha$ (amino acids 82-167), hRXR $\alpha$ (amino acid 130223 ), and hTR $\beta$ (amino acids 97-207) DNA fragments were produced by PCR. Templates in these reactions were RS-hRAR $\alpha$, RS-hTR $\beta$, and RS-hRXR $\alpha$ (Giguere et al. 1987; Thompson and Evans 1989; Mangelsdorf et al. 1990). The production of the chimeric DBDs involved two subsequent PCR steps according to a strategy that has been described (Higuchi et al. 1990). The PCR fragments were cut with BamHI and EcoRI and cloned in BamHI/EcoRI-cut pGEX-2T (Pharmacia). All DBD constructs were verified by sequencing. A similar strategy was used to produce a PCR product that encodes a fragment of RXRa but contains the GR P-box. This fragment was cloned into RShRXR $\alpha$ cut with SacI and SalI to yield RXR-G. The construct was verified by sequencing.

\section{Cotransfection assays}

CV-1 cells were maintained in Dulbecco's modified Eagle medium (DMEM) supplemented with $10 \%$ bovine calf serum (BCS). Transfections were performed by a calcium phosphate coprecipitation technique as described previously (Umesono et al. 1989). Cells were exposed to the precipitate for $6-8 \mathrm{hr}$, washed, and treated with phenol red-free DMEM, 10\% charcoal-resin treated BCS, and $0.1 \mu \mathrm{M} 3,3^{\prime}, 5$-triiodothyronine $\left\langle\mathrm{T}_{3}\right|$, $1 \mu \mathrm{M}$ all trans RA or ethanol as indicated in Figure 2. The following amounts of plasmid DNA were transfected per $10-\mathrm{cm}$ dish: $1.0 \mu \mathrm{g}$ of reporter, $1.0 \mu \mathrm{g}$ of expression plasmid, $5 \mu \mathrm{g}$ of $\mathrm{CMX}-\beta \mathrm{gal}$, and $8 \mu \mathrm{g}$ of $\mathrm{pGEM} 4$ vector.

\section{Bacterial expression}

Wild-type DBDs were expressed in bacteria as fusions with glutathione $S$ transferase (GST) using the pGEX-2T expression vector (Pharmacia). BL21 (DE3)plysS cells containing the pGEX-2T expression vectors were induced for $3 \mathrm{hr}$ with $0.5 \mathrm{mM}$ IPTG, and the pelleted cells were lysed and the lysate clarified by centrifugation for $1 \mathrm{hr}$ at 45,000g in a Ti60 (Beckman) rotor. Crude bacterial lysates containing the fusion protein were loaded onto a gluthathione-Sepharose column (Pharmacia). The column was washed, and fusion protein was eluted according to the manufacturers instructions, except that GST protein was cleaved from the DBD proteins using thrombin (Sigma), which was included in the elution buffer.

\section{DNA-binding assays}

For gel mobility retardation assays, indicated species of proteins were incubated with binding buffer, which contained $10 \mathrm{~mm}$ Tris (pH 8.0), $40 \mathrm{~mm} \mathrm{KCl}, 0.05 \%$ NP-40, 6\% glycerol, $1 \mathrm{~mm}$ DTT, $0.2 \mu \mathrm{g}$ of poly[d(I-C)] (Pharmacia). Approximately $0.5-1 \mathrm{ng}$ of ${ }^{32} \mathrm{P}$-labeled probe, which was labeled to a specific activity of about $1-5 \times 10^{8} \mathrm{cpm} / \mu \mathrm{g}$ by fill-in reaction with the Klenow fragment, was added to the reaction and incubated on ice for 20 $\mathrm{min}$. The reaction was then loaded into $4-8 \%$ nondenaturing polyacrylamide gels in $0.25 \times$ (low stringency) or $0.5 \times$ (high stringency) TBE running buffer. After electrophoreses, the gel was dried for autoradiography. The following oligonucleotides 
and their complements were ${ }^{32} \mathrm{P}$-labeled and used as probes as indicated (half-sites are indicated in bold): TREp, AGCTTCAGGTCATGACCTGAGAGCT; MLV TRE, AGCTCAGGGTCATTTCAGGTCCTTGAAGCT; $\beta R E 2$, AGCTTAAGGGTTCAAAAGTTCACTCGCAT; $\beta R E 3$, AGCTTAAGGGTTCAGAAAGTTCACTCGCAT; $\beta$ RE4, AGCTTAAGGGTTCACGAAAGTTCACTCGCAT; $\beta R E$ or $\beta$ RE5 (natural), AGCTTAAGGGTTCACCGAAAGTTCACTCGCAT.

\section{Acknowledgments}

We thank Dr. Steve Kliewer for purified RAR and RXR DBDs, and for many useful discussions. We thank Drs. Michael McKeown, Beverly Emerson, and members of the Evans laboratory for suggestions on the preparation of the manuscript and for useful discussions. We are grateful to $C$. Glass for communicating data prior to publication. T.P. is supported by a long term fellowship from the European Molecular Biology Organization (EMBO). R.M.E. is an investigator, and P.N.R. is a research associate of the Howard Hughes Medical Institute at the Salk Institute for Biological Studies. This work was supported by National Institutes of Health.

The publication costs of this article were defrayed in part by payment of page charges. This article must therefore be hereby marked "advertisement" in accordance with 18 USC section 1734 solely to indicate this fact.

\section{References}

Baker, A.R., D.P. McDonnell, M. Hughes, T.M. Crisp, D.J. Mangelsdorf, M.R. Haussler, J.W. Pike, J. Shine, and B.W. O'Malley. 1988. Cloning and expression of full-length cDNA encoding human vitamin D receptor. Proc. Natl. Acad. Sci. 85: 3294-3298.

Benbrook, D., E. Lernhardt, and M. Pfahl. 1988. A new retinoic acid receptor identified from a hepatocellular carcinoma. Nature 333: 669-672.

Brand, N., M. Petkovich, A. Krust, P. Chambon, H. de The, A. Marchio, P. Tiollais, and A. Dejean. 1988. Identification of a second human retinoic acid receptor. Nature 332: 850-853.

Bugge, T.H., J. Pohl, O. Lonnoy, and H.G. Stunnenberg. 1992. RXR alpha, a promiscuous partner of retinoic acid and thyroid hormone receptors. $E M B O J$. 11: 1409-1418.

Cooney, A.J., S.Y. Tsai, B.W. O'Malley, and M.J. Tsai. 1992. Chicken ovalbumin upstream promoter transcription factor (COUP-TF) dimers bind to different GTCA response elements, allowing COUP-TF to repress hormonal induction of the vitamin D3, thyroid hormone, and retinoic acid receptors. Mol. Cell. Biol. 12: 4153-4163.

Dahlman-Wright, K., A.P.H. Wright, J. Carlstedt-Duke, J.-A. Gustafsson. 1991. Protein-protein interactions facilitate DNA-binding by the GR DNA binding domain. J. Biol. Chem. 265: 14030-14035.

Danielsen, M., L. Hinck, and G.M. Ringold. 1989. Two amino acids within the knuckle of the first zinc finger specify DNA response element activation by the glucocorticoid receptor. Cell 57: 1131-1138.

de Thé, H., M.M. Vivanco-Ruiz, P. Tiollais, H. Stunnenberg, and A. Dejean. 1990. Identification of a retinoic acid responsive element in the retinoic acid receptor beta gene. Nature 343: 177-180.

Durand, B., M. Saunders, P. Leroy, M. Leid, and P. Chambon. 1992. All-trans and 9-cis retinoic acid induction of CRABPII transcription is mediated by RAR-RXR heterodimers bound to DR1 and DR2 repeated motifs. Cell 71: 73-85.
Evans, R.M. 1988. The steroid and thyroid hormone receptor superfamily. Science 240: 889-895.

Fawell, S.E., J.A. Lees, R. White, and M.G. Parker. 1990. Characterization and colocalization of steroid binding and dimerization activities in the mouse estrogen receptor. Cell 60: 953-962.

Forman, B.M., C.-R.Yang, M. Au, J. Casanova, J. Ghysdael, and H.H. Samuels. 1989. A domain containing leucine-zipperlike motifs mediate novel in vivo interactions between the thyroid hormone and retinoic acid receptors. Mol. Endocrinol. 3: 1610-1626.

Giguere, V., E.S. Ong, P. Segui, and R.M. Evans. 1987. Identification of a receptor for the morphogen retinoic acid. Nature 330: 624-629

Glass, C.K., J.M. Holloway, O.V. Devary, and M.G. Rosenfeld. 1988. The thyroid hormone receptor binds with opposite transcriptional effects to a common sequence motif in thyroid hormone and estrogen response elements. Cell 54: 313323.

Glass, C. K., S.M. Lipkin, O.V. Devary, and M.G. Rosenfeld. 1989. Positive and negative regulation of gene transcription by a retinoic acid-thyroid hormone receptor heterodimer. Cell 59: 697-708.

Hermann, T., B. Hoffmann, X.K. Zhang, P. Tran, and M. Pfahl. 1992. Heterodimeric receptor complexes determine 3, 5, 3'triiodothyronine and retinoid signaling specificities. Mol. Endocrinol. 6: 1153-1162.

Heyman, R.A., D.J. Mangesldorf, J.A. Dyck, R.B. Stein, G. Eichele, R.M. Evans, and C. Thaller. 1992.9-cis retinoic acid is a high affinity ligand for the retinoid $\mathrm{X}$ receptor. Cell 68: 397-406.

Higuchi, R. 1990. Recombinant PCR. In PCR protocols, a guide to methods and applications (ed. M.A. Innis, D. H. Gelfand, J. J. Sninsky, and T. J. White), pp. 177-184, Academic Press, Inc., San Diego, CA.

Höög, C., F.J. Calzone, A.E. Cutting, R.J. Britten, and E.H. Davidson. 1991 Gene regulatory factors of the sea urchin embryo. II. Two dissimilar proteins, p3A1 and p3A2, bind to the same target sites that are required for early territorial gene expression. Development 112: 351-364.

Isseman, I. and S. Green. 1990. Activation of a member of the steroid hormone receptor superfamily by peroxisome proliferators. Nature 347: 645-650.

Kliewer, S.A., K. Umesono, D.J. Mangesldorf, and R.M. Evans. 1992a. Retinoid X receptor interacts with nuclear recepors in retinoic acid, thyroid hormone and vitamin D3 signaling. Nature 355: 446-449.

Kliewer, S.A., K. Umesono, D.J. Noonan, R.A. Heyman, and R.M. Evans. 1992b. Convergence of 9-cis retinoic acid and peroxisome proliferator signaling pathways through heterodimer formation of their receptors. Nature 358: 771-774.

Krust, A., P. Kastner, M. Petkovich, A. Zelent, and P. Chambon. 1989. A third human retinoic acid receptor, hRAR-g. Proc. Nat1. Acad. Sci. 86: 5310-5314.

Kumar, V. and P. Chambon. 1988. The estrogen receptor binds tightly to its responsive element as a ligand-induced homodimer. Cell 55: 145-156.

Laudet, V., A. Begue, C. Henry-Duthoit, A. Joubel, P. Martin, D. Stehelin, and S. Saule. 1991. Genomic organization of the human thyroid hormone receptor alpha (c-erbA-1) gene. $\mathrm{Nu}$ cleic Acids Res. 19: 1105-1112.

Lee, M.S., S.A. Kliewer, J. Provencal, P.E. Wright, and R.M. Evans. 1993. Structure of the retinoid X receptor $\alpha$ DNA binding domain: A helix required for homodimeric DNA binding. Science 260: 1117-1120.

Lehmann, J.M., B. Hoffman, and M. Pfahl. 1991. Genomic or- 
ganization of the retinoic acid receptor gamma gene. Nucleic Acids Res. 19: 573-578.

Leid, M., P. Kastner, R. Lyons, H. Nakshatri, M. Saunders, T. Zacharewski, J.Y. Chen, A. Staub, J.M. Garnier, S. Mader, and P. Chambon. 1992. Purification, cloning and RXR identity of the HeLa cell factor with which RAR or TR heterodimers to bind target sequences efficiently. Cell 68: 377 395.

Levin, A.A., L.J. Sturzenbecker, S. Kazmer, T. Bosakowski, C. Huselton, G. Allenby, J. Speck, C. Kratzeise, M. Rosenberger, and A. Lovey. 1992. 9-cis retinoic acid stereoisomer binds and activates the nuclear receptor RXR alpha. Nature 355: 359-361.

Luisi, B.F., W.X. Xu, Z. Otwinowski, L.P. Freedman, K.R. Yamamoto, and P.B. Sigler. 1991. Crystallographic analysis of the interaction of the glucocorticoid receptor with DNA. Nature 352: 497-505.

Mader, S., P. Leroy, J.-Y. Chen, and P. Chambon. 1993. Multiple parameters control the selectivity of nuclear receptors for their response elements. J. Biol. Chem. 268: 591-600.

Mangelsdorf, D.J., E.S. Ong, J.A. Dyck, and R.M. Evans. 1990. A nuclear receptor that identifies a novel retinoic acid response pathway. Nature 345: 224-229.

Mangelsdorf, D.J., K. Umesono, S.A. Kliewer, U. Borgmeyer, E.S. Ong, and R.M. Evans. 1991. A direct repeat in the cellular retinol-binding protein type II gene confers differential regulation by RXR and RAR. Cell 66: 555-561.

Mangelsdorf, D.J., U. Borgmeyer, R.A. Heyman, J.Y. Zhou, E.S. Ong, A.E. Oro, A. Kakizuka, and R.M. Evans. 1992. Characterization of three RXR genes that mediate the action of 9-cis retinoic acid. Genes \& Dev. 6: 329-344.

Marks, M.S., P.L. Hallenbeck, T. Nagata, J.H. Segars, E. Appella, V.M. Nikodem, and K. Ozato. 1992. H-2RIIBP (RXR-beta) heterodimerization provides a mechanism for combinatorial diversity in the regulation of retinoic acid and thyroid hormone responsive genes. EMBO J. 11: 1419-1435.

Näär, A.M., J.-M. Boutin, S.M. Lipkin, V.C. Yu, J.M. Holloway, C.K. Glass, and M.G. Rosenfeld. 1991. The orientation and spacing of core DNA-binding motifs dictate selective transcriptional responses to three nuclear receptors. Cell 65: 1267-1279.

Nagpal, S., M. Saunders, P. Kastner, B. Durand, H. Nakshatri, and P. Chambon. 1992. Promoter context- and response element-dependent specificity of the transcriptional activation and modulating functions of retinoic acid receptors. Cell 70: 1007-1019.

Petkovich, M., N.J. Brand, A. Krust, and P. Chambon. 1987. A human retinoic acid receptor which belongs to the family of nuclear receptors. Nature 330: 444-450.

Sap, J., A. Munos, J. Scmitt, H. Stunnenberg, and B. Vennström. 1989. Repression of transcription mediated at a thyroid hormone response element by the v-erb-A oncogene product. Nature 341: 242-244.

Sarkar, G. and S.S. Sommer. 1989. Access to a messenger RNA sequence or its protein product is not limited by tissue or species specificity. Science 244: 331-334.

Sladek, F.M., W.M. Zhong, E. Lai, and J.E. Darnell, Jr. 1990. Liver-enriched transcription factor HNF-4 is a novel member of the steroid hormone receptor superfamily. Genes \& Dev. 4: 2353-2365.

Smith, W.C., H. Nakshatri, P. Leroy, J. Rees, and P. Chambon. 1991. A retinoic acid response element is present in the mouse cellular retinol binding protein I (mCRBPI) promoter. EMBO I. 10: 2223-2230

Sucov, H.M., K.K. Murakami, and R.M. Evans. 1990. Characterization of an autoregulated response element in the mouse retinoic acid receptor type beta gene. Proc. Natl. Acad. Sci. 87: 5392-5396.

Thompson, C.C. and R.M. Evans. 1989. Trans-activation by thyroid hormone receptors: Functional parallels with steroid hormone receptors. Proc. Natl. Acad. Sci. 86: 3494-3498.

Tini, M., G. Otulakowski, M.L. Breitman, L.-C. Tsui, and V. Giguere. 1993. An everted repeat mediates retinoic acid induction of the $\gamma \mathrm{F}$-crystallin gene: Evidence of a direct role for retinoids in lens development. Genes \& Dev. 7: 295-307.

Tsai, S.Y., J. Carlstedt-Duke, N.L.Weigelm, K. Dahlman, J.-A. Gustafsson, M.-J. Tsai, and B.W. O'Malley. 1988. Molecular interactions of steroid hormone receptor with its enhancer element: Evidence for receptor dimer formation. Cell 55: 361-369.

Umesono, K. and R.M. Evans. 1989. Determinants of target gene specificity for steroid/thyroid hormone receptors. Cell 57: 1139-1146.

Umesono, K., V. Giguere, C.K. Glass, M.G. Rosenfeld, and R.M. Evans. 1988. Retinoic acid and thyroid hormone induce gene expression through a common responsive element. Nature 336: $262-265$

Umesono, K., K.K. Murakami, C.C. Thompson, and R.M. Evans. 1991. Direct repeats as selective response elements for the thyroid hormone, retinoic acid, and vitamin D3 receptors. Cell 65: 1255-1266.

van der Leede, B.M., G.E. Folkers, F.A.E. Kruyt, and P.T. van der Saag. 1992. Genomic organization of the human retinoic acid receptor b2. Biochem. Biophys. Res. Comm. 188: 695702.

Vivanco Ruiz, M.M., T.H. Bugge, P. Hirschmann, and H.G. Stunnenberg. 1991 Functional characterization of a natural retinoic acid responsive element. EMBO I. 10: 3829-3838.

Weinberger, C., C.C. Thompson, E.S. Ong, R. Lebo, D.J. Gruol, and R.M. Evans. 1986. The c-erb-A gene encodes a thyroid hormone receptor. Nature 324: 641-646.

Wilson, T.E., R.E. Paulsen, K.A. Padgett, and J. Milbrandt. 1992. Participation of non-Zn finger residues in DNA-binding by two nuclear orphan receptors. Science 256: 107-110.

Yao, T.-P., W.A. Segraves, A. E. Oro, M. McKeown, and R.M. Evans. 1992. Drosophila ultraspiracle modulates ecdysone receptor function via heterodimer formation. Cell 71: 63-72.

Yu, V.C., C. Delsert, B. Andersen, J.M. Holloway, O.V. Devary, A.M. Näär, S.Y. Kim, J.M. Boutin, C.K. Glass, and M.G. Rosenfeld. 1991. RXR beta: A coregulator that enhances binding of retinoic acid, thyroid hormone and vitamin $D$ receptors to their cognate response elements. Cell 657: 1251-1266.

Zhang, X.K., B. Hoffmann, P.B. Tran, G. Graupner, and M. Pfahl. 1992a. Retinoid X receptor is an auxiliary protein for thyroid hormone and retinoic acid receptors. Nature 355: 441-446.

Zhang, X.K., J. Lehmann, B. Hoffmann, M.I. Dawson, J. Cameron, G. Graupner, T. Hermann, P. Tran, and M. Pfahl. $1992 \mathrm{~b}$. Homodimer formation of retinoid X receptor induced by 9-cis retinoic acid. Nature 358: 587-591. 


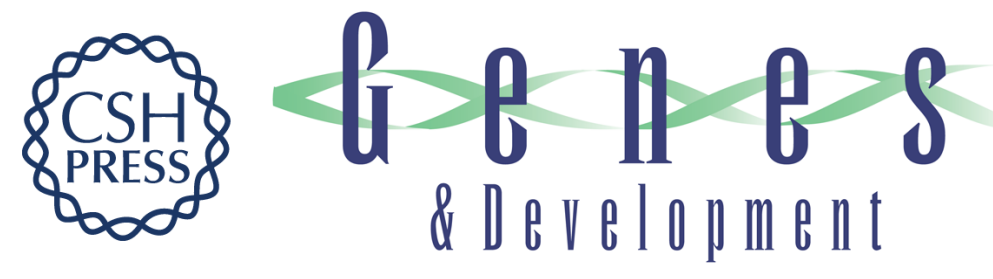

\section{Determinants for selective RAR and TR recognition of direct repeat HREs.}

T Perlmann, P N Rangarajan, K Umesono, et al.

Genes Dev. 1993, 7:

Access the most recent version at doi:10.1101/gad.7.7b.1411

References This article cites 56 articles, 14 of which can be accessed free at:

http://genesdev.cshlp.org/content/7/7b/1411.full.html\#ref-list-1

License

Email Alerting

Service

Receive free email alerts when new articles cite this article - sign up in the box at the top right corner of the article or click here.

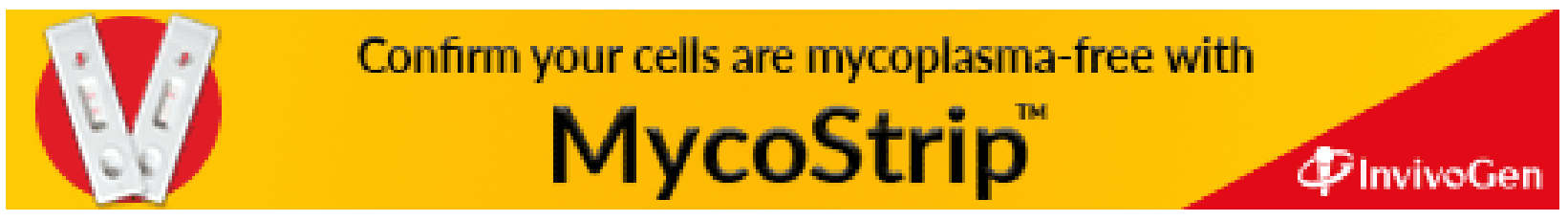

